\title{
Adoção de Práticas Ágeis em um Ambiente Tradicional: Um Estudo de Caso
}

\author{
Carlos Eduardo Azevedo Costinhas ${ }^{1}$, Gleison Santos ${ }^{1,2}$ \\ ${ }^{1}$ Departamento de Informática Aplicada - CCET \\ ${ }^{2}$ Programa de Pós-Graduação em Informática - PPGI \\ UNIRIO - Universidade Federal do Estado do Rio de Janeiro \\ Av. Pasteur 458, Urca - CEP 22290-240 - Rio de Janeiro - RJ - Brasil \\ \{carloseduardo.dasilva, gleison.santos\} @uniriotec.br
}

\begin{abstract}
It is not easy to convince an organization to change its development paradigm to adopt agile methodologies. It necessary planning and execution of coordinate actions. This paper presents a software process improvement initiative regarding the adoption of agile practices on the software development team of a telecom organization. The results include the approximation of the technical and business areas, improvement of communication and activities management, optimization of work capacity, reduction of aversion to change, and management support to deploy process improvement.
\end{abstract}

Resumo. Convencer uma organização a mudar o paradigma de desenvolvimento para adoção de metodologias ágeis pode não ser trivial e requer planejamento e execução de ações coordenadas. Este artigo apresenta uma iniciativa de melhoria de processos de software com foco na adoção de práticas ágeis em uma equipe de desenvolvimento de uma grande empresa de telecomunicações. Resultados obtidos incluem: aproximação das áreas técnicas e de negócio; melhorias na comunicação e gestão de atividades; otimização da capacidade de trabalho; redução da rejeição às mudanças e apoio das gerências para implantação de melhorias nos processos.

\section{Introdução}

Apesar de frequentes relatos de sucesso no uso de metodologias ágeis para incorporar mudanças, muitas organizações ainda utilizam metodologias convencionais para desenvolver software. A aplicação de práticas ágeis não é trivial, pois trata de mudanças na cultura organizacional e no ambiente de trabalho. Sua adoção, portanto, deve contar com apoio da organização e com planejamento que torne possível a implantação de mudanças graduais, reduzindo o impacto das mudanças propostas para a equipe. Dessa forma, convencer uma organização a mudar de paradigma de desenvolvimento requer a execução de ações que possibilitem indicar as necessidades de mudança, além de planejamento e monitoração de ações coordenadas para a melhoria dos processos.

Este artigo apresenta uma iniciativa de melhoria de processos de software com foco na adoção de práticas ágeis em uma equipe de desenvolvimento de software de uma empresa de grande porte do segmento de telecomunicações. Dentre os problemas identificados estavam: a dificuldade com o planejamento da equipe, causados pela baixa eficiência dos controles utilizados na gestão de atividades; a dificuldade para a revisão dos requisitos do produto durante seu processo de desenvolvimento, baseado no modelo cascata; insatisfação da Área de Negócios com os projetos de desenvolvimento de sof- 
tware realizados na empresa e a baixa taxa de resposta do processo de desenvolvimento às necessidades de mudanças no mercado. Foram executados 4 ciclos de melhoria, pensados de forma a atender expectativas das equipes envolvidas e, ao mesmo tempo, minimizar a possível rejeição às mudanças. Dentre os objetivos dessa iniciativa pode-se destacar: disseminar na equipe os conceitos e práticas propostos pelas metodologias e frameworks ágeis; reduzir a rejeição da equipe às mudanças de procedimentos a serem adotadas; evoluir o controle de projetos e atividades da equipe visando organizar e melhorar a visibilidade das tarefas em andamento; e melhorar a comunicação da equipe visando reduzir o tempo de resolução de problemas, através da troca de conhecimentos dos membros mais experientes com os membros menos experientes.

Além dessa introdução, a Seção 2 apresenta algumas metodologias ágeis; a Seção 3 apresenta o contexto da organização em questão, os ciclos da iniciativa de melhoria e os principais resultados; por fim, a Seção 4 apresenta as considerações finais.

\section{Metodologias Ágeis}

As metodologias ágeis partem do princípio que a ocorrência de mudanças é uma constante e não uma exceção. A predisposição é tratar mudanças de uma forma geral, incluindo todos os aspectos envolvidos. Estudos apontam que projetos podem incorporar as mudanças com mais facilidade e demonstrar valor ao negócio de forma mais eficiente do que os projetos que utilizam processos convencionais (DYBA et al., 2009). Além disso, técnicas de gerenciamento ágil de projetos podem ser combinadas com técnicas convencionais, permitindo maior flexibilidade do processo de desenvolvimento.

O Scrum assume que o conhecimento vem da experiência e a tomada de decisões é feita com base no que é conhecido. O desenvolvimento do produto é feito de forma iterativa, em ciclos denominados sprints. As funcionalidades a serem implementadas são mantidas em uma lista, chamada backlog do produto. No início de cada sprint, é feita uma reunião de planejamento onde é identificado seu escopo. A cada início de dia, o time de desenvolvimento realiza uma reunião breve, denominada reunião diária, para discutir o que foi feito no dia anterior, identificar impedimentos e priorizar o trabalho do dia. Ao final do sprint, o time apresenta as funcionalidades implementadas em uma reunião de revisão e, por fim, há uma reunião de retrospectiva, para identificar o que funcionou bem e o que pode ser melhorado (SCHWABER et al., 2011).

O desenvolvimento enxuto de software (do inglês, lean software development) é baseado nos conceitos de produção enxuta (cujo foco é a eliminação de desperdícios do processo de produção) e desenvolvimento enxuto de produtos. O desenvolvimento enxuto de produtos tem foco nas etapas de criação do produto, do conceito à entrega final, sendo mais próximo da engenharia de software. Os sete princípios adaptados ao desenvolvimento de software são: elimine desperdícios, estimule o aprendizado, tome decisões o mais tarde possível, entregue o produto o mais rápido possível, dê poder de decisão à equipe, inclua a qualidade no processo e otimize o todo (PETERSEN, 2010).

Kanban é um termo japonês que significa sinal visual. Uma de suas grandes características é evidenciar os problemas existentes no processo (SILVA et al., 2013). As equipes que o adotam precisam estar atentas ao processo aplicado para visualizar pontos de melhoria e adaptações, para que o processo possa fluir de forma satisfatória. Segundo KNIBERG et al. (2009), o Kanban tem apenas três prescrições: visualize o fluxo de trabalho atual; limite o fluxo de trabalho; acompanhe e gerencie o fluxo de trabalho. 


\section{A Organização e as Etapas do Ciclo de Melhoria}

A iniciativa de melhoria de processos de software relatada nesse artigo foi realizada em uma empresa privada de grande porte do segmento de telecomunicações, que atua no Brasil há 18 anos e possui como foco a telefonia móvel e a banda larga. A empresa possui mais de 10.000 colaboradores em todo o país, principalmente nos estados do Rio de Janeiro e São Paulo. A área de Gerência de Tecnologia da Informação é responsável por desenvolvimento e manutenção de sistemas relacionados ao registro e cobrança de serviços de telefonia fixa. Esta área (tratada no texto como Área Técnica) possui interação com uma Fábrica de Software e com uma Área de Negócios. A Área Técnica tem 4 integrantes: 1 coordenador da área, 1 analista sênior e 2 analistas plenos, sendo um deles o primeiro autor deste artigo e condutor da iniciativa de melhoria de processos relatada.

Cada integrante da Área Técnica é responsável por um ou mais sistemas, que podem estar relacionados a uma ou mais Áreas de Negócio. O processo de software em uso, baseado no cascata, é composto das fases Iniciação, Análise, Design, Construção, Aceitação e Implantação. A única etapa não realizada pela Área Técnica é a codificação, feita pela Fábrica de Software contratada. Documentos relevantes incluem: Declaração de Escopo (na Iniciação); Descrição Funcional e Cenários de UAT (produtos da Análise); Especificação funcional, Plano de Entrega e Plano de Testes (produtos do Design); Especificação Técnica, Código, Material de Treinamento e do usuário, Planos e evidências de testes e Registro de entrega formal (criados na Construção);

A Fábrica de Software possui três integrantes: 2 desenvolvedores seniores (sendo 1 responsável pela coordenação da equipe) e 1 desenvolvedor júnior. A Área de $\mathrm{Ne}$ gócio de gestão de riscos, convidada para participar por ser a menor e mais receptiva a experimentar novos métodos, tem sete integrantes (um gerente, dois analistas seniores, uma assistente sênior e três assistentes juniores). A execução envolveu o gerente e um analista sênior. O papel de usuário foi desempenhado pelo analista sênior e o andamento foi acompanhado pelo gerente da área.

A iniciativa de melhoria realizada foi dividida em 7 etapas, descritas a seguir (mais informações podem ser obtidas em [COSTINHAS 2013]). Diferentemente de melhorias verticais, onde a organização decide implantar um modelo de maturidade e, muitas vezes, adotam práticas ágeis no escopo dos processos (ver [Catunda et al., 2011; Silva et al., 2011]), melhorias horizontais podem ser mais sensíveis a motivação e envolvimento dos participantes. Assim, a estratégia foi pensada para atender expectativas das equipes envolvidas e, ao mesmo tempo, minimizar a possível rejeição às mudanças.

\subsection{Etapas 1 e 2 - Análise do Perfil da Organização e Percepção dos Problemas}

A primeira etapa do ciclo de melhoria consistiu em realizar uma revisão da literatura sobre as práticas, metodologias e frameworks ágeis, com foco no Scrum, no Kanban e no desenvolvimento enxuto de software, visando identificar que conceitos e práticas poderiam ser aplicados para atingir os objetivos propostos. A partir da análise de artigos (ver, por exemplo, [ABRANTES e TRAVASSOS 2011]), foram selecionadas as práticas mais citadas que poderiam ser aplicáveis ao ambiente da organização (ver Tabela 1). Os questionários e outros mecanismos utilizados podem ser vistos em (COSTINHAS, 2013), não sendo apresentados nesse artigo por restrições de espaço.

Na segunda etapa foi realizada uma pesquisa com as equipes envolvidas nos 
projetos de desenvolvimento de software na organização selecionada, a fim de identificar o perfil das pessoas, os problemas existentes na organização e pontuar quais critérios eram considerados críticos para o sucesso dos projetos, que foram priorizados utilizado o modelo AHP (Analytic Hierarchy Process) (VARGAS, 2010). A partir dos resultados, foram definidos os ciclos de melhoria executados nas etapas seguintes (ver Seção 3.2).

Todos os integrantes da Área Técnica e da Fábrica de Software possuem experiência superior a cinco anos na área de TI (fato que auxilia a execução do projeto por contar com uma equipe com bom nível de maturidade profissional). Em relação ao conhecimento sobre as metodologias e frameworks ágeis, todos conheciam, de alguma forma, o Scrum e o XP (Extreme Programming), dois conheciam o Kanban e ninguém conhecia o lean. Foi solicitada também a indicação de que práticas ágeis eram conhecidas (ver Tabela 1, o número entre parênteses indica quantos reportaram conhecê-las). Além das opções previamente apresentadas, foi citada também a definição de "pronto".

Tabela 1 - Práticas Ágeis Selecionadas e Nível de Conhecimento da Equipe

\begin{tabular}{|l|l|}
\hline \multicolumn{1}{|c|}{ Foco } & \multicolumn{1}{c|}{ Práticas } \\
\hline Requisitos & Divisão em funcionalidades (3), Backlog do produto (1) \\
\hline Fase de design & Metáforas do sistema (1) \\
\hline Fase de construção & $\begin{array}{l}\text { Padrões de codificação (5), Código coletivo (1), Integração contínua (2), } \\
\text { Programação em par (4), Refatoração do código (5), Entregas curtas (4), } \\
\text { Desenvolvimento dirigido por testes (2), Automação de Testes (4) }\end{array}$ \\
\hline Fase de testes & Automação de testes (4) \\
\hline Organização e ambiente & Cliente presente (1), Ritmo sustentável (1), Times multidisciplinares (4) \\
\hline Gerenciamento do projeto & $\begin{array}{l}\text { Jogo do planejamento (2), Visibilidade do projeto (2), Retrospectivas (3), } \\
\text { Reuniões Scrum (5) e Reuniões diárias em pé (5) }\end{array}$ \\
\hline
\end{tabular}

Um questionário foi utilizado para obter a percepção das equipes sobre se o processo de desenvolvimento de software conseguia auxiliar no atendimento dos objetivos do projeto, com relação a: Prazo; Custo; Escopo; Satisfação do Cliente; Qualidade do Produto e Mudanças de Escopo. Todos os 7 entrevistados indicaram que o processo atrapalhava a obtenção dos objetivos relacionados a escopo e mudanças de escopo. Com relação à satisfação do cliente, 1 entrevistado indicou que o processo auxilia pouco, 3 indicaram que o processo não auxilia ou é indiferente e 3 que o processo atrapalha.

Em relação aos critérios relevantes para o sucesso em um projeto de desenvolvimento, para a Área de Negócio, os principais (86\%) são: entregar o produto sem bugs, entregar o produto que melhor atende às necessidades do cliente e absorver mudanças de escopo. Para a Área Técnica (85\%): entregar o produto que melhor atende às necessidades do cliente, entregar o produto de acordo com o escopo definido, absorver mudanças de escopo e entregar o produto sem bugs. Para a Fábrica de Software (84\%): entregar o produto dentro do valor orçado, de acordo com o escopo definido, sem bugs identificados e no prazo previsto.

Foi considerado que o processo não favorecia a revisão das necessidades do negócio ao longo de sua execução, tornando qualquer mudança nos requisitos prejudicial. O histórico de projetos da organização apresentava problemas frequentes, decorrentes desta inflexibilidade às mudanças e das dificuldades com o controle de atividades da equipe. Cenário reforçado pelo resultado dos questionários aplicados, que demonstram a percepção de baixa taxa de sucesso dos projetos executados.

Para tratar os problemas, a estratégia adotada foi decompor a iniciativa de melhoria em ciclos, para minimizar a rejeição da equipe às mudanças na rotina de trabalho 
e proporcionar um período de adaptação e aprendizado entre cada ciclo.

Durante esta etapa, o ambiente da empresa sofreu algumas mudanças que favoreceram a iniciativa: (i) atualização do modelo do documento de descrição funcional (tornando os requisitos, as regras de negócio e os casos de uso explícitos e incluindo o registro da rastreabilidade entre eles); (ii) mudança física das equipes para o mesmo local; e (iii) interesse das equipes na experimentação de novas práticas.

\subsection{Etapas 3 a 6 - Os Ciclos de Melhoria}

A Figura 1 apresenta o cronograma de execução dos ciclos de melhoria. As etapas de monitoração e acompanhamento de cada ciclo são contínuas e não estão representadas.

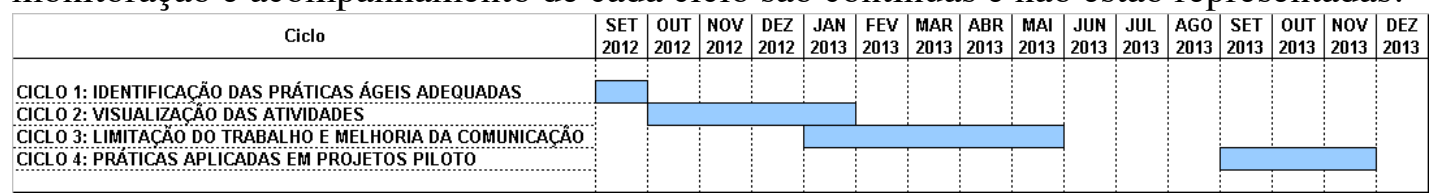

Figura 1 - Cronograma de execução dos ciclos de melhoria

Na terceira etapa, o primeiro ciclo de melhoria foi planejado e executado buscando identificar que práticas ágeis poderiam ser aplicadas para atingir os objetivos de melhoria. Neste ciclo, as práticas foram analisadas levando em consideração o perfil da organização e das equipes, com base no resultado da pesquisa realizada anteriormente. Evitou-se a seleção de práticas não adequadas ao ambiente de forma a manter o macroprocesso de desenvolvimento, que não poderia ser alterado por ser o oficial da empresa. Assim, optou-se por propor mudanças no micro-processo que não gerassem impactos negativos no macro-processo. As práticas selecionadas foram utilizadas nos ciclos seguintes, levando em consideração seus objetivos específicos, conforme Tabela 2.

\begin{tabular}{|c|c|c|c|}
\hline Etapa & Objetivos & Práticas selecionadas & Justificativas \\
\hline $\begin{array}{l}\text { CICLO 2: VISUALIZAÇÃO DAS } \\
\text { ATIVIDADES }\end{array}$ & $\begin{array}{l}\text { - Melhorar na visualização das atividades da equipe; } \\
\text { - Facilitar a alocação de recursos; } \\
\text { - Permitir a identificação de gargalos no fluxo. }\end{array}$ & - Visibilidade do projeto; & $\begin{array}{l}\text { A equipe da Área Técnica possui dificuldade no } \\
\text { planejamento e visualização das atividades da } \\
\text { equipe, em função da baixa eficiência de seus } \\
\text { controles. Isto gera impacto negativo na execução } \\
\text { dos projetos. }\end{array}$ \\
\hline $\begin{array}{l}\text { CICLO 3: LIMITAÇÃO DO TRABALHO E } \\
\text { MELHORIA DA COMUNICAÇÃO }\end{array}$ & - Eliminação de gargalos no fluxo; & $\begin{array}{l}\text { - Ritmo sustentável; } \\
\text { - Cliente presente; } \\
\text { - Reuniões de pé; } \\
\text { - Retrospectivas } \\
\text { - Visibilidade do projeto. }\end{array}$ & $\begin{array}{l}\text { Melhorar a comunicação da equipe para antecipar } \\
\text { problemas e compartihar conhecimento. Além de } \\
\text { ajustar a carga de trabalho para tornar o ambiente } \\
\text { mais saudável, evitando horas extras e atrasos por } \\
\text { excesso de paralelismo de atividades. }\end{array}$ \\
\hline $\begin{array}{l}\text { CICLO 4: PRÁTICAS APLICADAS EM } \\
\text { PROJETOS PILOTO }\end{array}$ & $\begin{array}{l}\text { - Aplicar todas as práticas na execução de um projeto, } \\
\text { e não só em seu monitoramento; } \\
\text { - Aumentar a transparência no processo; } \\
\text { - Melhorar a satisfação da Área de Negócios; } \\
\text { - Reduzir os impactos das mudanças no processo. }\end{array}$ & \begin{tabular}{|l|} 
- Ritmo sustentável; \\
- Cliente presente; \\
- Reuniões de pé; \\
- Retrospectivas \\
- Visibilidade do projeto; \\
- Divisão em funcionalidades.
\end{tabular} & $\begin{array}{l}\text { Atuar na melhoria da satisfação e sensação de } \\
\text { progresso da Área de Negócios, além de adaptar } \\
\text { o processo para receber melhor qualquer tipo de } \\
\text { mudança durante a fase de desenvolvimento. }\end{array}$ \\
\hline
\end{tabular}

$\mathrm{Na}$ quarta etapa, o segundo ciclo de implantação foi planejado e executado. O foco deste ciclo foi a dificuldade de planejamento e visualização de atividades que a equipe da Área Técnica possuía, em função da baixa eficiência dos controles adotados anteriormente. A opção de atuar nestes problemas foi porque a melhoria dos controles internos afetaria diretamente a gestão dos projetos de forma positiva.

A prática selecionada para aplicação foi a de visibilidade do projeto, proposta pelo Kanban, que também busca atender ao princípio da eliminação de desperdícios proposto pelo desenvolvimento enxuto de software. Para minimizar possíveis rejeições às mudanças propostas, não foi citado nome de nenhuma metodologia ou ferramenta, se referindo apenas como uma nova maneira de controlar as atividades. Em 3 semanas de trabalho, o quadro kanban substituiu completamente o controle anterior feito com planilhas, facilitando a visualização completa do fluxo de trabalho e permitindo à equipe 
identificar e atuar no primeiro gargalo. Os benefícios percebidos após aplicação desta prática foram: (i) Melhoria na visualização dos projetos e atividades da área, em suas respectivas fases; (ii) Melhoria na alocação da equipe, ao permitir identificar facilmente as atividades sob responsabilidade de cada integrante; (iii) Identificação visual de gargalos no fluxo; (iv) Facilitação e armazenamento da comunicação em cada projeto específico; (iv) Eliminação dos controles realizados anteriormente por meio de planilhas com a centralização das informações nas descrições de cada projeto.

As dificuldades encontradas durante esta aplicação foram: (i) a resistência inicial da equipe às mudanças em sua rotina (minimizada ao evitar citar o nome dos métodos e práticas utilizadas e o incentivo à equipe para que participasse ativamente das propostas de melhoria); (ii) o período de manutenção de dois controles em paralelo enquanto o novo controle não era utilizado por toda a equipe.

O sucesso na aplicação desta prática tornou a equipe mais receptiva a novas mudanças. Também preparou o ambiente para a aplicação das práticas de cliente presente (buscando uma maior transparência do processo) e ritmo sustentável (tentando obter uma maior qualidade no trabalho e satisfação das equipes). Assim, a estratégia de ciclos e de priorização dos itens mais vistos como problemas também se mostrou adequada.

Na quinta etapa, o terceiro ciclo de implantação foi planejado e executado. As práticas adotadas foram a limitação do trabalho em andamento (WIP), proposta pelo Kanban, e a melhoria na comunicação da equipe, com base em práticas do Scrum, em princípios do Manifesto Ágil e do desenvolvimento enxuto de software. O principal ponto positivo do envolvimento das demais áreas com as práticas propostas foi o interesse da Área de Negócios em utilizar o Kanban para gestão de suas atividades não relacionadas com TI. Isso favoreceu a troca de conhecimento entre as áreas e pode reforçar a importância da melhoria de processos na organização.

Os demais benefícios percebidos com a aplicação destas práticas foram: (i) conhecimento da velocidade da equipe em cada etapa do processo de desenvolvimento; (ii) redução da ociosidade e da sobrecarga de trabalho através do ajuste e monitoramento constante do WIP; (iii) antecipação de atrasos e resolução de problemas ao favorecer a comunicação entre todos os membros da equipe; (iv) compartilhamento de informações entre membros da equipe e outras áreas da empresa; (v) aumento da sensação de progresso da Área de Negócios ao acompanhar mais de perto as atividades da Área Técnica; (vi) aumento da confiança da Área de Negócios na Área Técnica ao permitir a transparência dos processos e atividades; (vii) revisão semanal de prioridades do negócio e atividades relacionadas na Área Técnica, garantindo que os esforços da área de TI estejam alinhados com a estratégia da Área de Negócios.

As dificuldades encontradas foram: (i) entendimento e correta aplicação do conceito de WIP pela equipe, solucionado com o compartilhamento de conteúdos de apoio (sites, blogs, apresentações e artigos na internet); (ii) resistência inicial de um membro da equipe com o acompanhamento de atividades sob sua responsabilidade, tratada e solucionada pelo coordenador da área; (iii) período de adaptação da Área de Negócio aos novos conceitos apresentados, que foi reduzido com a realização de palestras para compartilhar o conhecimento das práticas utilizadas, apresentando um conteúdo adaptado à realidade da Área de Negócio utilizando a prática de metáforas; (iv) limitação do plano gratuito da ferramenta utilizada (quadro virtual kanban) para utilização plena dos recursos necessários, contornada com adaptação do uso de informações nos projetos. 
Apesar das melhorias propostas nos ciclos 2 e 3 terem sido aplicadas na prática, executadas ao longo de 8 meses em projetos já iniciados, ainda era necessário executar um ou mais projetos por completo, utilizando todas a práticas propostas em conjunto para avaliar seu impacto e adequabilidade na organização. Dessa forma, a sexta etapa consistiu em planejar e executar o quarto ciclo de implantação, que buscou atender o objetivo principal deste trabalho. Foram selecionados dois projetos piloto (denominados A e B) e aplicadas práticas relacionadas com os requisitos e desenvolvimento do produto, além de práticas relacionadas com a organização e ambiente de trabalho.

As execuções dos projetos A e B foram realizadas sem maiores problemas, conforme cronograma. Um ponto negativo para o Projeto A, mas positivo para a experiência, foi o atraso de um dia na etapa de testes em função da indisponibilidade do ambiente de testes. Neste caso, o usuário teve contato por meio das reuniões com dificuldades que podem surgir durante o desenvolvimento, mas nem sempre são percebidas na entrega final devido ao atraso ser geralmente absorvido pela fábrica através de horas extras. Para o Projeto B, as entregas parciais também foram benéficas. Após a entrega do $2^{\circ}$ módulo e antes do início do $3^{\circ}$, foi realizada uma mudança de escopo em uma reunião de revisão de entrega. Apesar de a mudança simples, esse fato foi considerado um ponto positivo, pois se o desenvolvimento fosse realizado em apenas um módulo, a adequação seria feita após a conclusão do desenvolvimento, gerando custos de nova entrega.

\subsection{Etapa 7 - Retrospectiva}

A sétima etapa consistiu em realizar reuniões de retrospectiva com os participantes e verificar se a adoção das práticas atenderam aos objetivos da iniciativa de melhoria. A Tabela 3 apresenta discussão sobre objetivos de cada ciclo e principais pontos positivos.

Tabela 3 - Objetivos de Melhoria e Principais Pontos Positivos Reportados

\begin{tabular}{|l|l|}
\hline Etapa & \multicolumn{1}{c|}{ Objetivos e Pontos Positivos } \\
\hline Etapa 2 & Permitiu uma visão geral sobre a percepção das áreas envolvidas nos projetos. \\
\hline Ciclo 2 & Objetivos atingidos pela implantação do quadro kanban e foco na identificação de gargalos. \\
\hline Ciclo 3 & $\begin{array}{l}\text { Objetivos atingidos. Reuniões periódicas foram implementadas, facilitando comunicação entre } \\
\text { equipes e gargalos reduzidos (pelo uso do WIP) tratando paralelismo de atividades. } \\
\text { Transparência da Área de TI com a Área de Negócio. }\end{array}$ \\
\hline Ciclo 4 & $\begin{array}{l}\text { Foi atingida parcialmente a redução do impacto de mudanças no processo, pois a proposta só } \\
\text { pôde ser aplicada em dois projetos piloto. É necessária a gestão de mais projetos utilizando } \\
\text { todas as práticas. Os demais objetivos foram atingidos, com a iniciativa de aproximar a Área } \\
\text { de Negócio do ambiente de desenvolvimento, utilizando as visitas diárias e entregas curtas. } \\
\text { Aumento da sensação de progresso do projeto para Área de Negócio. Aplicação de novos } \\
\text { métodos com a preocupação de não impactar os processos internos da fábrica. }\end{array}$ \\
\hline
\end{tabular}

Por fim, a Tabela 4 apresenta considerações sobre os critérios de sucesso (ver Seção 3.1) na visão de cada equipe participante da iniciativa de melhoria de processos.

Tabela 4 - Objetivos de Melhoria e Pontos Positivos Reportados

\begin{tabular}{|l|l|}
\hline \multicolumn{1}{|c|}{ Equipe } & \multicolumn{1}{c|}{ Considerações } \\
\hline Área de & $\begin{array}{l}\text { A aplicação desta proposta contribuiu positivamente para os critérios de satisfação do usuário } \\
\text { e mudáças de escopo, citados como um dos mais relevantes para o sucesso de um projeto. O } \\
\text { critério de qualidade não foi abordado, pois não foi caracterizado como um problema } \\
\text { relevante, segundo as percepções da Área de Negócio sobre o processo atual. }\end{array}$ \\
\hline $\begin{array}{l}\text { Área } \\
\text { Técnica }\end{array}$ & $\begin{array}{l}\text { A aplicação desta proposta contribuiu positivamente para os critérios de satisfação do usuário } \\
\text { e gerência de escopo, citados como um dos mais relevantes para o sucesso de um projeto }\end{array}$ \\
\hline $\begin{array}{l}\text { Fábrica } \\
\text { de } \\
\text { Software }\end{array}$ & $\begin{array}{l}\text { A aplicação desta proposta não gerou impacto negativo nos seus processos internos, que não } \\
\text { poderiam ser alterados por questões contratuais. Ainda assim, todos os ciclos puderam ser } \\
\text { executados trazendo ganhos para a Área Técnica e Área de Negócio. }\end{array}$ \\
\hline
\end{tabular}




\section{Considerações Finais}

Este artigo apresentou uma experiência de melhoria de processos de software com foco na adoção de práticas ágeis em uma equipe de desenvolvimento de software de uma grande empresa. A estratégia para minimizar rejeição às mudanças foi incentivar o envolvimento das equipes no planejamento das melhorias e na execução das atividades, além de não citar nomes de metodologias ou frameworks antes da prática ser aplicada. Para reduzir a concorrência da aplicação das melhorias com atividades diárias, a duração do projeto foi prolongada e o esforço diário reduzido para que todos os ciclos propostos ocorressem. Objetivos secundários atendidos incluem: novas práticas e conceitos disseminados entre as equipes envolvidas; rejeição às mudanças de rotina minimizadas; evolução na gestão das atividades; e comunicação entre as equipes otimizada.

Com base nos resultados obtidos, nota-se que é possível adotar práticas ágeis em um ambiente denominado tradicional, com processos e metodologias já definidas, sem a necessidade de adoção de uma metodologia ou framework por completo. As principais dificuldades identificadas foram a rejeição natural da equipe durante a proposta do primeiro ciclo de melhoria e a concorrência das atividades diárias com as propostas deste projeto. O critério chave para o sucesso desta implantação foi o incentivo das gerências envolvidas e a receptividade das áreas participantes às novas propostas. Os controles evoluídos durante esta iniciativa continuarão sendo aplicados. Como próximo passo, a organização deve adaptar e aplicar estas práticas em projetos maiores e mais complexos, para verificar se os ganhos da aplicação em projetos curtos serão mantidos.

\section{Agradecimentos}

Os autores agradecem à FAPERJ pelo auxílio financeiro (projeto E-26/110.438/2014).

\section{Referências}

COSTINHAS, C. E. A. (2013), "Um Estudo de Caso sobre Adoção de Práticas Ágeis Em um Ambiente Tradicional”, Monografia de Final de Curso de Graduação, Bacharelado em Sistemas de Informação DIA/BSI/UNIRIO, Rio de Janeiro - RJ. Disponível em (verificado em 24/04/2014): http://bsi.uniriotec.br/tcc/201312Costinhas.pdf.

ABRANTES, J. F.; TRAVASSOS, G. H. (2011), Common agile practices in software processes. In: International Symposium on Empirical Software Engineering and Measurement (ESEM), p. 355-358.

DYBA, T; DINGSOYR, T (2009). What do we know about agile software development?. IEEE Software, v. 26, n. 5, p. 6-9.

SCHWABER, K. (1995) SCRUM Development Process. In: Proceedings of the 10th Annual ACM Conference on Object Oriented Programming Systems, Languages, and Applications (OOPSLA).

VARGAS, R. V.; IPMA-B, P. M. P. (2010). Utilizando a programação multicritério (Analytic Hierarchy Process-AHP) para selecionar e priorizar projetos na gestão de portfólio. PMI Global Congress. p1-22.

PETERSEN, K (2010). Implementing Lean and Agile software development in industry. Blekinge Institute of Technology Doctoral Dissertation Series.

SILVA, D. V. S.; SANTOS, F. A. O.; NETO, P. S. (2012) Os benefícios do uso de Kanban na gerência de projetos de manutenção de software. Simpósio Brasileiro em Sistemas de Informação (SBSI 2012), São Paulo - SP, p. 337-347.

KNIBERG, H.; SKARIN, M. Kanban and Scrum making the most of both. Managing Editor: Diana Plesa. Enterprise software development series. InfoQ. USA. ISBN 978-0-557-13832-6, 2010.

CATUNDA, E., NASCIMENTO, C., CERDEIRAL, C., SANTOS, G., NUNES, E., SCHOTS, N. C. L., SCHOTS, M., ROCHA, A. R. (2011) "Implementação do Nível F do MR-MPS com Práticas Ágeis do Scrum em uma Fábrica de Software", X Simpósio Brasileiro de Qualidade de Software (SBQS 2011), Curitiba-PR, pp. 417-424.

SILVA, T., MAGElA, R., SANTOS, G., SCHOTS, N. C. L., ROCHA, A. R. (2011) "Implantação do Nível F do MR-MPS Combinando Características do Processo Unificado com Práticas SCRUM", VII Workshop Anual do MPS - WAMPS (WAMPS 2011), Campinas-SP, pp. 54-61. 